\title{
ANÁLISE DE RISCOS ERGONÔMICOS NO SETOR DE ACABAMENTO EM UMA CONFECÇÃO DE CAMISARIA
}

ANALYSIS OF ERGONOMIC RISKS IN THE FINISHING SECTOR IN A T-SHIRT

MANUFACTURE

Josiane Aparecida Cardoso de Souza ${ }^{1}$ Priscila França Gonzaga ${ }^{2}$ Mauro Lúcio Mazini Filho ${ }^{3}$

Recebido em: 16 ago. 2017

Aceito em: 10 jun. 2018

RESUMO: O objetivo desse trabalho foi analisar as condições ergonômicas no setor de acabamento de uma confecção de camisaria feminina situada na Zona da Mata Mineira. Através da pesquisa de campo qualitativa e quantitativa, utilizou-se questionário adaptado contendo dados sobre perfil, condições de trabalho e saúde dos trabalhadores, o check list de Couto, o mapa corporal de Corllet, a NR 17, além de análise Antropométrica e identificação dos riscos ergonômicos. Os principais resultados deste, mostraram a necessidade de mudanças do posto de trabalho, implantação da ginástica laboral, entre outras medidas.

Palavras-chave: Ergonomia. Posturas. LER/DORT.

ABSTRACT: The goal of this present work was that of evaluating the ergonomic or biotechnological conditions in the finishing end department of a clothes factory skilled in social female shirts, located in the east of the state of Minas Gerais. By means of a qualitative and quantitative, through the utilization of a specific questionnaire comprising data on profile, work and health working conditions, as well as the Check List of Couto, the Corllet bodily map, the NR 17, Anthropometrics Analysis, beyond identification of ergonomic risks. The main results of this, demonstrate the need changes in workstations, the deployment of labor gymnastic, between steps necessaries.

Keywords: Ergonomics. Postures. RSI / WMSD.

\section{INTRODUÇÃO}

Os riscos ergonômicos são aqueles que podem interferir na relação harmônica entre trabalho e o homem, podendo ocasionar danos à saúde do trabalhador alterando seu estado fisiológico ou emocional, ou comprometer a segurança no ambiente de trabalho e a produtividade da empresa (MARQUES, 2011).

O estudo sobre Lesões Músculo-Esqueléticas Ligadas ao Trabalho (LMELT) tem

\footnotetext{
1 Faculdades Integradas de Cataguase.

2 Faculdades Integradas de Cataguase.

3 Universidade Federal de Juiz de Fora.
} 
sido atenção de distintas avaliações ergonômicas, independentemente se são lesões agudas ou cumulativas, sendo considerado risco ergonômico que tem por conseqüência uma lesão ocasionada ao longo do tempo devido fatores acumulativos (SOARES, SILVA, 2012).

Patussi (2005) afirma que o desconforto ou a dor causada pelo exercício da função, podem ser considerados como indicadores na percepção de problemas no corpo do funcionário, além de servir como alerta de problemas futuros de saúde.

Coury (1994) alega que os sintomas musculoesqueléticos detectados podem estar relacionados à sensação de peso, formigamento, percepção física desagradável e fadiga. De acordo com Vitta, Bertaglia, Padovani (2008), para diminuir e/ou prevenir tais sintomas é necessário planejar e/ou replanejar as tarefas realizadas, o ambiente físico de trabalho, etc.

A ergonomia busca relacionar o entendimento entre o homem e o ambiente do trabalho através da aplicação de princípios, em que tem como objetivo trazer segurança, bem estar e conforto ao trabalhador. Esta é regida pela Norma Regulamentadora - NR 17 (1978).

O presente trabalho objetivou analisar o ambiente ergonômico do setor de acabamento de uma empresa do ramo de confecção de camisas sociais femininas na Zona da Mata Mineira. Para isso foi realizado um estudo quali-quantitativo de caráter explicativo utilizando procedimentos técnicos de levantamento. Desta forma identificaram-se os riscos ergonômicos, as dores causadas pelo trabalho, variáveis antropométricas de cada setor, o risco do profissional de desenvolver LER/DORT e investigações com os mobiliários de acordo com a NR 17.

\section{MATERIAIS E MÉTODOS}

A empresa está no mercado desde 1994, fabrica roupas na cidade com marca própria e para outras empresas. É composta por 60 pessoas, sendo 55 mulheres e 5 homens, com faixa etária entre 16 a 59 anos.

Os 60 colaboradores são distribuídos em tais setores: financeiro, 2 funcionários (2 mulheres); produção, 31 funcionários (4 homens e 27 mulheres); modelagem (1 mulher); corte, 2 funcionários ( 2 mulheres); pilotagem, 2 funcionários (2 mulheres) e acabamento 22 funcionários ( 1 homem e 21 mulheres). Juntos chegam a produzir 9900 peças por mês.

A abordagem da pesquisa é quali-quantitativa, pois traduz em números opiniões e informações para classificá-las e analisá-las, considerando uma relação dinâmica entre o mundo real e o sujeito.

Quanto ao objetivo da pesquisa, ele é de caráter explicativo; pois visa identificar fatores colaborativos ao determinar a ocorrência de fenômenos, aprofundar o conhecimento da realidade e utilizar procedimentos técnicos de levantamento, envolvendo interrogação 
direta das pessoas cujo comportamento se deseja conhecer.

O desenvolvimento desta pesquisa foi consentido tanto pela direção da empresa, que documentou por escrito um termo de autorização, quanto pelos funcionários, que se disponibilizaram e tiveram enorme satisfação em participar. Foi solicitado a todos participantes da pesquisa que lessem e assinassem um Termo de Consentimento Livre e Esclarecido (TCLE) respeitando assim os cuidados éticos legais de acordo com a resolução no 466 de 2012 no TCLE.

\section{AMOSTRA}

A pesquisa foi realizada no setor de acabamento em que trabalham 22 funcionários. Participaram todos na análise antropométrica, mas apenas 5 responderam ao Questionário (Teixeira, 2012) e ao Diagrama de Corllet. As características amostrais dos dados antropométricos como: idade, peso, altura, IMC e do tempo de serviço foram calculados através de média $(\bar{x})$ e o desvio-padrão $(s)$.

\section{INSTRUMENTOS DE PESQUISA}

Para verificação dos parâmetros antropométricos utilizou-se uma balança (Filizola Brasil) para aferir o peso em quilogramas $(\mathrm{Kg})$, com precisão de 0,1 kg e um estadiômetro (Sanny, Brasil) para verificação da estatura, e para essa medida em $(\mathrm{cm})$ a precisão foi regulada em $0,1 \mathrm{~cm}$. Sendo estas variáveis antropométricas coletadas, seguindo as recomendações sugeridas por Gordon et al., (1988) e WHO (1998).

Foi calculado o Índice de Massa Corporal (IMC) dos funcionários. O valor é obtido da divisão entre a massa corporal pela altura ao quadrado. Analisando-se a em qual grupo se encaixa (peso normal, obesidade, etc.) o profissional, a fim de tomar decisões necessárias.

Para a avaliação musculoesquelética, foi utilizado o questionário de Couto (1995). Composto por 25 questões relacionadas à força com as mãos, postura no trabalho, repetitividade, entre outros. Ao final é realizado o somatório das respostas, que fornecem os dados de interpretação do risco de desenvolver LER/DORT, que varia desde ausência de risco até altíssimo risco dos fatores biomecânicos.

Foi utilizado um diagrama de corpo Corllet (1995), onde o funcionário assinala os locais de desconforto/dor, o grau de desconforto (nenhum, algum, moderado, bastante, intolerável) e o período que sentiu as respectivas dores/desconforto (últimos 30 dias, até 12 meses, mais de um ano).

Foi utilizado o questionário de Teixeira (2012) devidamente adaptado com os objetivos do estudo. Foi composto de três partes, assim distribuídas: dados sócios demográficos (sexo, idade, etc.); caracterizações das demandas das cargas de trabalho 
(função, tempo de trabalho, etc.); perfis de condições de saúde (queixas de desconforto relacionado ao trabalho).

Por fim, foram verificados mobiliários, equipamentos, ferramentas, organização do trabalho, entre outros, que se fazem necessárias para melhorias do posto de quanto como determina a NR 17.

Neste trabalho foram utilizados os métodos de estatística descritiva. $E$ as análises estatísticas foram realizadas no software computacional Excel 2007 para Windows.

\section{RESULTADOS E DISCUSSÃO}

\section{IDENTIFICAÇÃO DOS RISCOS ERGONÔMICOS NO SETOR DE ACABAMENTO UMA}

\section{CONFECÇÃO DE CAMISARIAS EM DONA EUZÉBIA-MG}

Depois de o tecido passar pelo setor de corte, setor de produção, ele vai para o setor de acabamento. $O$ acabamento é a seção onde são executadas as operações finais, com alguns componentes já unidos, este recebe os tecidos do setor de produção, visando à melhoria na qualidade ou complementação do produto. Dentre essas operações estão: casear, pregar botão, pregar etiqueta, passar e embalar. É realizada uma inspeção e limpeza, retirando pontos de linha em excesso ou até mesmo operações mal realizadas, de acordo com a figura 1 :

Figura 1: Execução do caseamento das camisas no setor de acabamento.

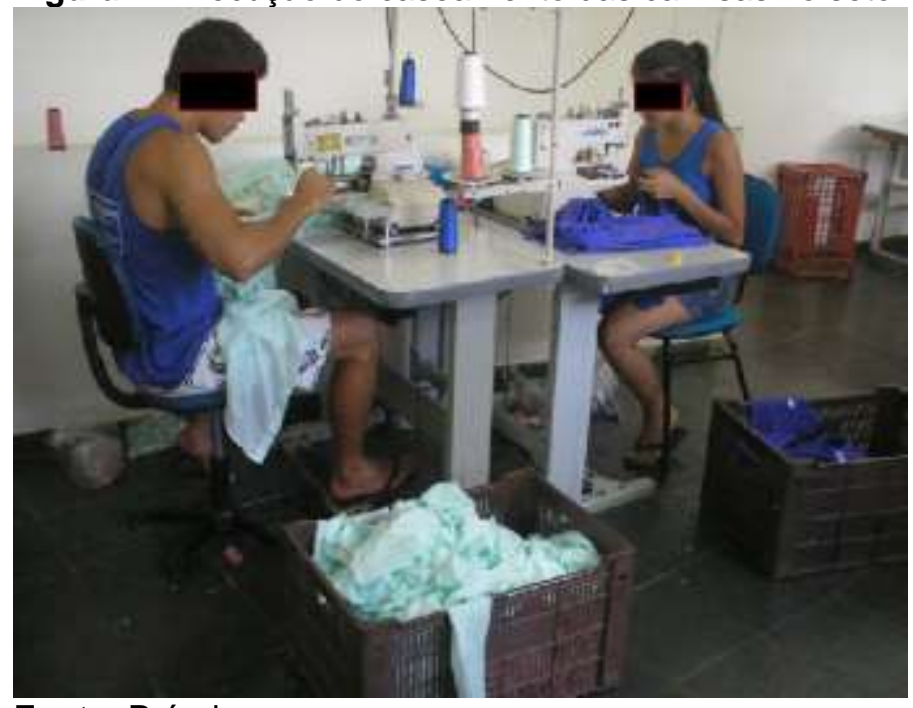

Fonte: Própria.

Como estabelece a NR 17 para trabalho manual sentado as bancadas, mesas, escrivaninhas devem ter fácil alcance e visualização pelo trabalhador. De acordo com a figura 1, no setor de acabamento, os caixotes onde são colocadas as peças prontas situamse muito abaixo do desejável, o que força o trabalhador a posturas inadequadas. 
Segundo Cunha (2013) em seu estudo realizado no setor de acabamento de uma confecção de roupas, foi verificado que as peças semi-prontas são colocadas em cima das coxas dos colaboradores para realização do trabalho, prejudicando assim seu desempenho e sua postura. Este sugere adaptações ao mobiliário do posto de trabalho de acordo com a NR 17, que propõem para trabalho manual sentado as bancadas, mesas, escrivaninhas e os painéis possuírem altura e características da superfície de trabalho compatíveis com o tipo de atividade, com distância requerida dos olhos ao campo de trabalho e com altura do assento.

O quadro 1 mostram as funções, as atividades executadas pelos funcionários no setor de acabamento e os respectivos riscos ergonômicos a quais estão submetidos.

Quadro 1: Funções, atividades e riscos ergonômicos no setor de acabamento na indústria de camisaria .

\begin{tabular}{|c|c|c|}
\hline FUNCূÃO & ATIVIDADE & RISCOSERGÔNOMICOS \\
\hline $\begin{array}{l}\text { Operador de } \\
\text { máquina } \\
\text { especial. }\end{array}$ & $\begin{array}{l}\text { Operam máquinas automáticas ou } \\
\text { semi-automáticas de caseamento e } \\
\text { travete, prega botões metálicos, } \\
\text { fazem etiquetagem. }\end{array}$ & $\begin{array}{l}\text { FISIOLÓGICAS: } \\
\text { - Posição fixa sentada por } \\
\text { longo tempo ou em pé; } \\
\text { - Movimentos Repetitivos; } \\
\text { - Exigência de Postura; } \\
\text { - Jornada de Trabalho longa; } \\
\text { PSíQUICAS } \\
\text { - Controle rigido de produção }\end{array}$ \\
\hline $\begin{array}{l}\text { Revisor de } \\
\text { arremate }\end{array}$ & $\begin{array}{l}\text { Faz o controle de qualidade do } \\
\text { produto, realizando a inspecão de } \\
\text { problemas a serem corrigidos. }\end{array}$ & $\begin{array}{l}\text { FISIOLÓGICAS: } \\
\text { - Posição de trabalho fixa em } \\
\text { pé ou sentado por longo } \\
\text { periodo. - Mbvimentos } \\
\text { repetitivos; } \\
\text { Exigência de postura; } \\
\text { - Jornada de trabalho longa. }\end{array}$ \\
\hline
\end{tabular}

Fonte: Própria

De acordo com o quadro 1, o trabalho é executado na posição em pé ou sentada , em alguns casos, com a altura da máquina muito baixa em relação ao piso, obriga assumir uma posição encurvada para visualização do campo de trabalho, que requer precisão.

Logo após as peças serem montadas e inspecionadas, estas vão para a passadoria, onde as peças são passadas, como mostra a figura 2. 
Figura 2: Passadoria, após as camisas já estarem prontas.

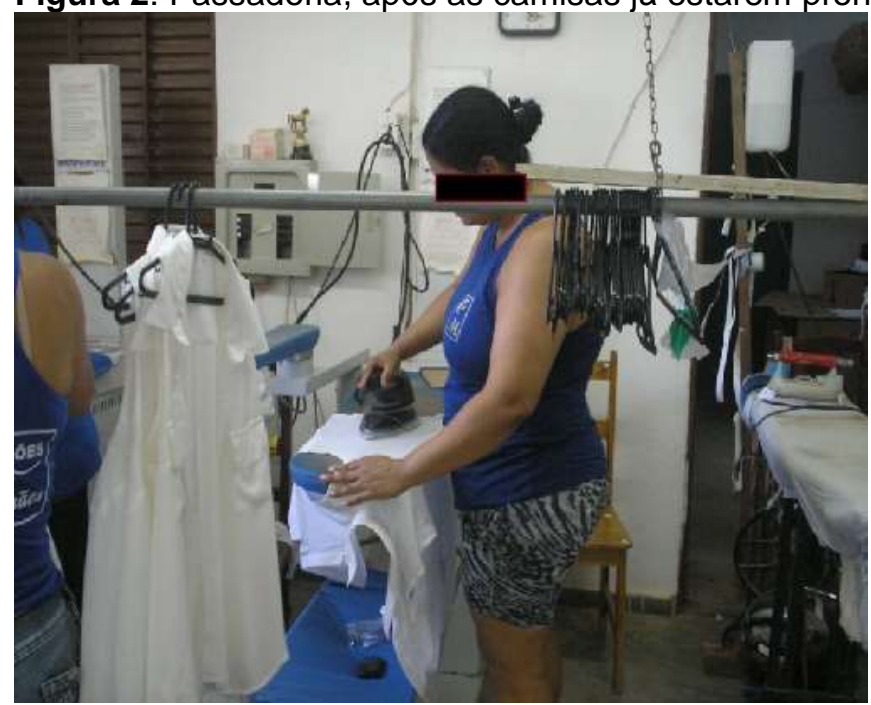

Fonte: Própria.

A NR 17 estabelece para trabalho manual que tenha de ser feito em pé a necessidade das bancadas serem de fácil alcance e visualização pelo trabalhador e ter características dimensionais que possibilitem posicionamento e movimentação adequados dos segmentos corporais. Como mostra a figura 2, as camisas a serem passadas são colocadas em cadeiras, o que exige do colaborador posturas inadequadas ao longo da jornada de trabalho. Além disso, é uma atividade repetitiva.

De acordo com Júnior (2006) na passadoria, os colaboradores sofrem com o ritmo de trabalho, movimentos repetitivos, trabalho na posição fixa em pé; as cargas físicas, relacionadas ao calor; as cargas psíquicas. O quadro mostra os riscos ergonômicos na passadoria, que entre eles estão a exigência da posição ortostática, movimentos repetitivos, serviço pesado em jornadas longas e de grande produção.

Quadro 2: Funções, atividades e riscos ergonômicos no setor de passadoria na indústria de camisaria .

\begin{tabular}{|l|l|l|}
\hline FUNCূAO & ATIVIDADE & RISCOS ERGÖNOMICOS \\
\hline Passador & $\begin{array}{l}\text { Realiza a passagem da roupa e } \\
\text { a dobra as peças passadas. }\end{array}$ & $\begin{array}{l}\text { FISIOLOGICAS } \\
\text { - Posição fixa em pé por longo tempo; } \\
\text { - Movimentos repe titivos; } \\
\text { - Exigência de postura; } \\
\text { - Jornada de trabalho longa; } \\
\text { - Esforço fisico pesado. } \\
\text { PŚQUICAS: } \\
\text { - Controle rigido da produção; }\end{array}$ \\
\hline $\begin{array}{l}\text { Auxiliar de } \\
\text { passador }\end{array}$ & $\begin{array}{l}\text { Abastece o setor de passadoria } \\
\text { de peças e dobra as peças } \\
\text { passadas e encaminha ao setor } \\
\text { de embalagem. }\end{array}$ & $\begin{array}{l}\text { - Posição fixa em pé por longo tempo; } \\
\text { - Movimentos repe titivos; } \\
\text { - Jornada de trabalho longa. }\end{array}$ \\
\hline
\end{tabular}

Fonte: Própria

Após as peças de roupas serem passadas, estas são dobradas e embaladas em 
sacos plásticos, caixas de papelão padronizadas. Esse tipo de embalagem depende da forma de peça que produz e outros critérios da empresa. A figura 3 mostra as funcionárias embalando as peças.

Figura 3: Embalagem das camisas.

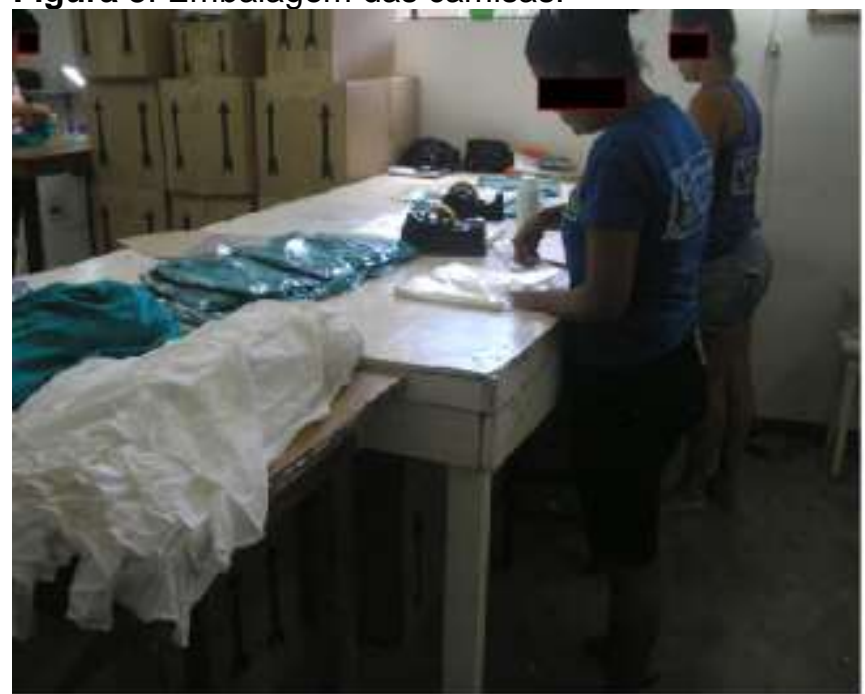

Fonte: Própria.

Conforme a NR 17 para as atividades em que os trabalhos devam ser realizados de pé, devem ser colocados assentos para descanso em locais em que possam ser utilizados por todos os trabalhadores durante as pausas. No momento de embalar o produto, não se encontra assentos disponíveis para descanso. Em seu trabalho realizado no setor de acabamento em uma confecção de roupas, Cunha (2013) afirma que neste setor, o trabalho é ortostático, sugerindo assentos para descanso de acordo com a NR 17.

O quadro 3 mostra a atividade que o embalador tem que realizar e os riscos ergonômicos que está exposto, entre eles movimentos repetitivos, carregamento de peso, posição ortostática.

Quadro 3: Funções, atividades e riscos ergonômicos no setor de embalagem e expedição na indústria de camisaria.

\begin{tabular}{|c|c|c|}
\hline FUNCূÃO & ATIVIDADE & RISCOSERGONÔMICOS \\
\hline Embalador & $\begin{array}{l}\text { Embala manualmente as peças } \\
\text { de roupas em sacolas plásticas e } \\
\text { após em caixas de papelão. }\end{array}$ & $\begin{array}{l}\text { FISOLÓGICAS: } \\
\text { - Levantamento e carregamento } \\
\text { de peso; } \\
\text { - Trabalho repetitivo; } \\
\text { - Exigência de postura; }\end{array}$ \\
\hline
\end{tabular}

Fonte: Própria 
CARACTERIZAÇÃO DA AMOSTRA PARA ANÁLISE ANTROPOMÉTRICA E TEMPO DE SERVIÇO

A Tabela 01 apresenta os valores de média, desvio padrão, máximos e mínimos, referentes aos 22 funcionários (100\%) do setor de acabamento que compuseram o universo amostral desta pesquisa.

Tabela 01 - Estatística Descritiva para uma amostra de 22 funcionários do setor de acabamento

\begin{tabular}{cccccccc}
\hline Estatística & Idade & Peso & Altura & IMC & Tempo do serviço \\
\hline Média & 36 & 62,9 & 1,6 & 24,38 & 4,54 anos \\
Desvio Padrão & 11,41 & 15,06 & 0,07 & 5,22 & 5,19 anos \\
Máximo & 51 & 97 & 1,82 & 36,96 & 14 anos \\
Minimo & 16 & 50 & 1,52 & 16,65 & 1 mês \\
\hline
\end{tabular}

Fonte: Dados da Pesquisa.

Como se pode observar, a idade dos funcionários variou entre 16 e 51 anos (36 $\pm 11,41$ anos).

Já o peso, variou entre 50 e $97 \mathrm{~kg}(62,9 \pm 15,06 \mathrm{~kg})$. E a altura variou entre 1,52 e $1,82 \mathrm{~m}(1,6 \pm 0,07 \mathrm{~m})$. Com esses dados, calculou-se o IMC, que ficou entre 16,65 e 36,96 $\mathrm{kg} / \mathrm{m}^{2}\left(24,38 \pm 5,22 \mathrm{~kg} / \mathrm{m}^{2}\right)$. Analisando-se a média, os funcionários estariam dentro da normalidade, ou seja, peso normal. Mas ao analisar o valor mínimo, percebe-se que o funcionário está muito abaixo do peso, já o valor máximo indica obesidade II. Portanto, ambos os casos exigem cuidados como: ir ao nutricionista e realizar exercícios físicos. Entretanto, se faz-se necessário estudar caso a caso para que medidas corretas sejam tomadas.

Segundo Cox (1987), o índice de massa corporal elevado pode ser um fator de risco independente para disco lombar herniado, ou seja, altura e massa corporal pesada podem ser contribuintes importantes para herniação dos discos intervertebrais lombares e classificados como fatores de riscos ás dores lombares.

Para a variável tempo de serviço, o tempo mínimo foi de 1 mês e o tempo máximo de 14 anos (4,54 $\pm 5,19$ anos).

\section{ANÁLISES DO QUESTIONÁRIO DE INVESTIGAÇÃO PROFISSIONAL ADAPTADO}

(TEXEIRA, 2012)

O turno da confecção é das $7 \mathrm{~h}$ às $17 \mathrm{~h} 30$ de segunda-feira à quinta-feira, $7 \mathrm{~h}$ ás 16h30min sexta. Existem três pausas formais durante a jornada: café da manhã (das $9 \mathrm{~h}$ às $9 \mathrm{~h} 10 \mathrm{~min}$ ), almoço (das $11 \mathrm{~h}$ às $12 \mathrm{~h} 30 \mathrm{~min}$ ) e café da tarde (das 15h30mim às 15h40min). 
Em épocas de grandes encomendas, são realizadas horas extras noturnas e nos sábados, e que, às vezes, são utilizadas como banco de horas para compensar os dias úteis entre feriados e final de semana, quando os trabalhadores são dispensados do trabalho.

No setor de acabamento dentre os cinco funcionários que participaram do questionário, três responderam que trabalham de 6 a 8 horas por dia e dois responderam que trabalham de 8 a 10 horas por dia.

Um dos fatores que podem causar danos à saúde pode estar ligado à inflexibilidade de postura do funcionário. No setor de acabamento $60 \%$ dos colaboradores afirmaram não possuírem flexibilidade na postura, pois este setor exige dos colaboradores a posição em pé em grande parte do horário de trabalho, o que pode acarretar em problemas de coluna, inchaço nos pés. E como consequência tem-se os afastamentos, absenteísmo, entre outros.

De acordo com Cavalcante (2006), em seu estudo, foram relacionados os custos referentes aos problemas detectados tais como absenteísmo, proporcional ao período de produção da coleção, correspondendo a 244 dias perdidos. O cálculo de impacto do absenteísmo na produção, também foi estimado considerando o potencial de trabalho dos funcionários faltosos, durante o período de produção da coleção. O custo relacionado a 418 peças defeituosas, a 1217 peças com pedidos cancelados pelo cliente, aos pedidos não faturados por falta de um tamanho ou cor, grande parte desses custos tem relação direta com a ausência de ergonomia e, portanto a correção das inconformidades traria benefícios à medida que minimizaria os custos relacionados aos problemas.

Pausas como beber água, ir ao banheiro não são realizadas por $20 \%$ dos funcionários do setor de acabamento. A norma regulamentadora NR 17, determina que nas atividades que exijam sobrecarga muscular estática ou dinâmica do pescoço, ombros, dorso e membros superiores e inferiores, devem ser incluídas pausas para descanso, pois são de fundamental importância para a saúde do colaborador no trabalho. A empresa deve se adequar a essa norma de uma maneira que a sua produção seja beneficiada, mas sem descumpri-la.

Segundo Couto e Cardoso (1995) as pausas são importantes a fim de evitar a sobrecarga músculo esqueléticas e a fadiga mental, geralmente expressa em irritabilidade, dificuldade para memorização, raciocínio e leitura.

Em função da postura, $40 \%$ dos colaboradores afirmaram trabalhar sempre sentados, $40 \%$ sempre em pé e $20 \%$ dos funcionários trabalham variando ambas as posições com maior tempo destinado ao trabalho em sentado. Cunha (2013) relata que os colaboradores que trabalham nesse setor, executam suas tarefas na posição sentada, ou de pé, pois são exigidas atividades musculares do dorso e do ventre. Todo o peso do corpo é suportado pela pele que cobre os ossos e posturas inadequadas provocam dores nos músculos.

No setor de acabamento $60 \%$ dos funcionários afirmaram sentir insatisfação na posição de execução do serviço. Segundo Cunha (2013) a postura dos colaboradores do 
setor de acabamento varia conforme a função de cada indivíduo. Litegui (1990) se propõem a refletir que a satisfação tem uma relação muito clara e intensa com aspectos da vida e do comportamento dos trabalhadores. Acredita-se que outros fatores possam estar relacionados com a satisfação do trabalho, como por exemplo, o lazer, o grau de exercício físico, o nível de consciência corporal e o estilo de vida.

\section{DIAGRAMA DE CORLLET (1995)}

As dores ocasionadas por motivos de trabalho foram relatadas por $60 \%$ dos funcionários e $40 \%$ afirmaram sentir desconforto, o que pode estar ligado diretamente com a inflexibilidade de $60 \%$ dos mesmos. O tempo que ocorre estes desconfortos ou dores foi referido por $40 \%$ dos funcionários no período dos últimos 30 dias, $40 \%$ nos últimos 12 meses e $20 \%$ há mais de um ano.

Segundo Maciel et al (2006), inúmeros problemas podem surgir decorrentes da realização de determinadas tarefas ou atos no ambiente de trabalho, que depende da atividade que está sendo realizada e do tempo que seu organismo está se submetendo a executá-la. Assim sugere-se que o surgimento de alguns desconfortos nos funcionários está diretamente ligado a atividade ser repetitiva e ao tempo em que as mesmas são realizadas.

O percentual de queixas de dores dos funcionários no setor e as regiões mais afetadas decorrente do seu trabalho na posição na qual executa sua tarefa, é apresentado no gráfico 1.

Gráfico 1 - Queixas relatadas pelos funcionários do setor de acabamento

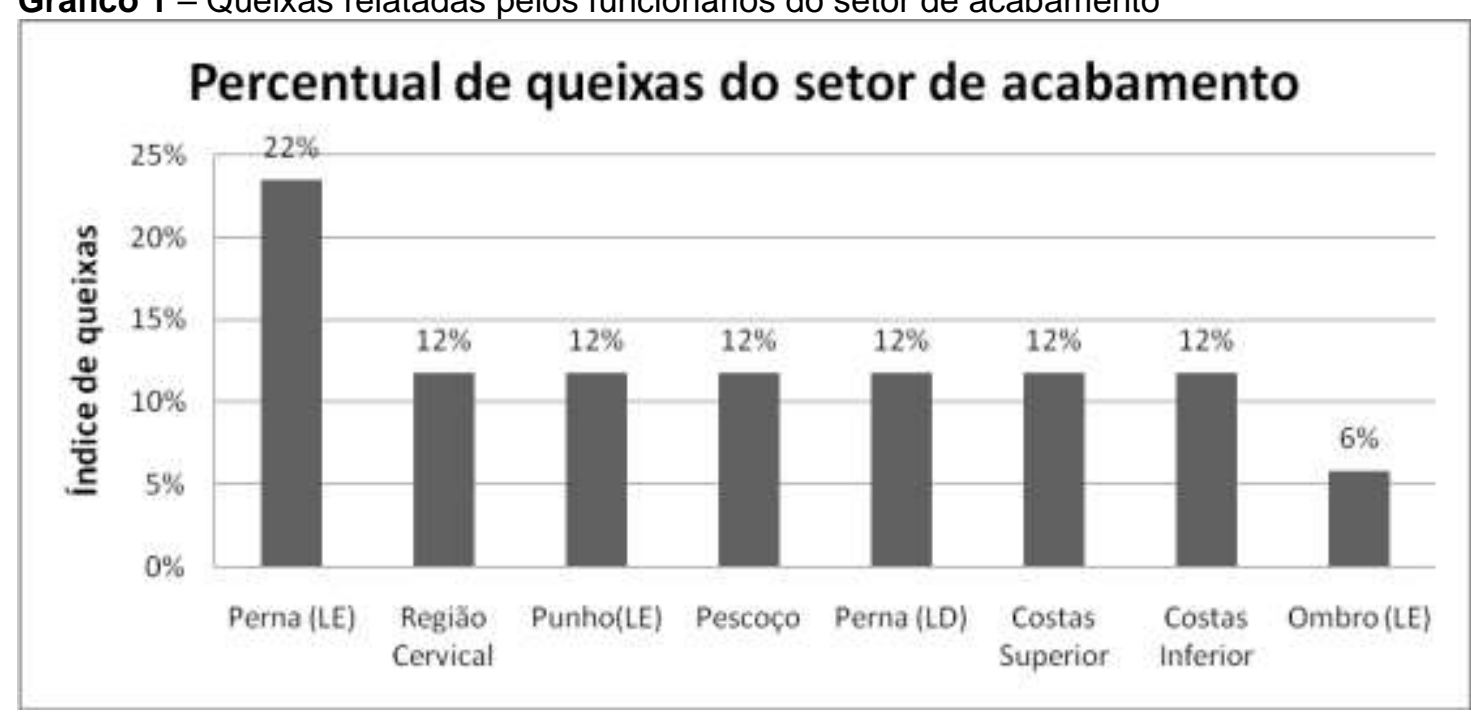

Dos cinco trabalhadores do setor de acabamento entrevistados pelo diagrama de Corllet, $100 \%$ dos trabalhadores informaram ter tido algum problema de dores no corpo, e as regiões com mais queixas foram: perna esquerda com $22 \%$ de queixas, as regiões cervical, punho, pescoço, perna direita, cotas superior, costas inferior com $12 \%$ e ombro com $6 \%$ de queixas. 
Observando um estudo de Paizante (2006), a frequência de dor osteomusculares nas trabalhadoras em confecção nos últimos 12 meses foram: coluna lombar (72,3\%); coluna dorsal (61,4\%); ombros (55,3\%); pescoço (54,1\%); pulsos/mãos (38,8\%); quadris/coxas $(36,5 \%)$; joelhos $(34,1 \%)$; tornozelos $(28,2 \%)$ e nos cotovelos $(3,5 \%)$. Esse estudo difere no índice de maior queixa de incidência de dores, que é na região das pernas, devido uma grande parte dos colaboradores no setor de acabamento trabalhar na posição ortostática, já as outras regiões de queixas apresentam semelhança com incidência na coluna lombar, pescoço, punho e pernas.

\section{ANÁLISE DO CHECKLIST COUTO (1995)}

Através do Checklist de Couto (1995), foi diagnosticado no setor de corte um somatório de 15 pontos, o que indica um fator biomecânico muito significativo, onde há alto risco dos funcionários desenvolverem doenças ocupacionais como LER/DORT.

Verificou-se na avaliação da postura de trabalho nesse setor, que os colaboradores inclinam muito sobre a mesa, apresentando posturas inadequadas na realização dos serviços de passadoria, arremate, revisão e empacotamento. Na avaliação do posto de trabalho verificou-se que as mesas se encontram muito baixa. A NR 17 afirma que o ambiente de trabalho deve ser de fácil alcance e visualização pelo trabalhador. Havendo assim a necessidade de mudanças na busca de maior conforto dos colaboradores, tais como, troca de mobiliários.

\section{CONSIDERAÇÕES FINAIS}

A ergonomia é um fator determinante no bom andamento dos processos fabris, se tornando mais presente e necessária não somente nas atividades corriqueiras organizacionais, mas em todo o conjunto de procedimentos.

As atividades exercidas pelos profissionais do setor de acabamento exigem postura ortostática, carregamento de peso, posições inadequadas, os movimentos são repetitivos e a longa jornada de trabalho pode ser exaustiva e trazer conseqüências tais como dores, absenteísmo, além de LER/DORT. Sugere-e que estas podem ser algumas das causas das dores que foram declaradas por $60 \%$ dos funcionários, entre elas estão a pena esquerda, pescoço, punho, costas inferior e superior.

Além disso, Diagrama de Couto (1995) mostrou ser uma função onde há alto risco de desenvolvimento de LER/DORT. O que se torna necessárias que medidas sejam tomadas rapidamente para não comprometer em grande escala a saúde dos funcionários.

Para o IMC, há necessidade de estudar cada funcionário para tomar medidas necessárias como consultas com o nutricionista e/ou atividades físicas. De acordo Organização Mundial da Saúde OMS (2004) a prática de atividade física regular e orientada 
reduz os riscos de doenças cardiovasculares, diabetes, hipertensão, câncer de cólon e mama, no controle de peso corporal e manutenção dos níveis de glicose sanguínea.

Trocar mesas, escrivaninhas, necessidade de assentos para descanso, apoio para os pés, cadeiras ajustáveis, posicionar os caixotes (em que são colocadas as peças prontas) no nível do cotovelo do funcionário são importantes no cumprimento da NR 17, mas principalmente para beneficiar a saúde dos funcionários.

\section{REFERÊNCIAS}

CARDOSO, D. D.; POPOLIM, F. D. Alterações da coluna vertebral relacionadas ao trabalho sentado em costureiras. 2006. 37f. Monografia (apresentada ao Centro Universitário Claretiano para a obtenção do título de graduado em fisioterapia). Batatais, 2006.

CAVALCANTE, Elizabete Fernandes. Avaliação do Custo da Produção em uma Indústria de Confecção Através da Análise Ergonômica do Trabalho. Curitiba, 2006.

COUTO, H. A. e CARDOSO, O. S. Censo De Ergonomia (1995).

CORLLET, E. Nigel. The evaluation of posture and its effects. In: Wilson, John R. Corllet, E. Nigel.Evaluation of human work - A practical ergonomics methodology. Taylor \& Francis: Londres,1995. Pp. $663-713$

COUTO, Hudson de Araújo. Ergonomia aplicada ao trabalho; o manual técnico da máquina humana. 2 v. Belo Horizonte: Ergo, 1995.

COURY HJCG. Programa auto-instrucional para o controle de desconfortos posturais em indivíduos que trabalham sentados [Tese]. Campinas (SP): Unicamp; 1994.

COX, J.M; TRIER, K.K. Exercise and smoking habits in patients with and without low back pain and leg pain. J. ManipulativePhysicalTher.1987; 10:239-244.

CUNHA, Leomar Cardoso. Avaliação da condição ergonômica específica do setor de acabamento de uma indústria de confecção de criciúma. Criciúma, 2013, p. 1-48.

GORDON, C.C; CHUMLEA, W.C; ROCHE, A.F. Stature, recumbent length, and weight. In: Lohman TG, Roche AF, Martorell R. (editors). Anthropometric standardization reference manual.Champaign: HumanKinetics Books. p. 3-8, 10, 1988.

JÚNIOR, Antônio Carlos Garcia. Condições de Trabalho e Saúde dos Trabalhadores na Indústria do Vestuário em Colatina - ES. Vitória, 2006, p. 1-130.

LITEGUI, J. Determinantes de La satisfacion laboral em emplegados de La administracion foral de navarra. UniversidadComplutensede Madrid, 1990.

MACIEL, A. C. C. et al.. Prevalência dos fatores associados à sintomatologia dolorosa entre profissionais da indústria têxtil. Revista Brasileira de epidemiologia. São Paulo, vol. 9, n 1 março 2006. 
MARQUES, Blake Charles Diniz;SAMPAIO, Priscila Goncalves Vasconcelos. Análise Ergonômica Do Trabalho Numa Fábrica De Produtos De Limpeza. MG. Belo Horizonte, 2011.

MINISTÉRIO DE TRABALHO. Normas Regulamentadoras de Segurança e Saúde no Trabalho. NR 17 Ergonomia. Disponível em:

http://www.mte.gov.br/Empregador/segsau/Legislacao/Normas/conteudo/nr17. Acesso em 25 out 2013.

PATUSSI, A. P. Definição de critérios de avaliação ergonômica para mesas de trabalho informatizado. 2005. 108 f. Dissertação (Mestrado em Engenharia de Produção) Universidade Federal do Rio Grande do Sul, Porto Alegre, 2005.

PAIZANTE, G. O. Análise dos fatores de risco da coluna lombar em costureiras de uma fábrica de confecção de moda íntima masculina no município de Muriaé - MG. 2006. 69f. Dissertação (Mestrado em meio ambiente e sustentabilidade) Centro Universitário de Caratinga. 2006.

PORTAL TRIBUTÁRIO EDITORA, Disponível em http://www.portaltributario.com.br/. Acesso em 20 de fevereiro de 2014.

SOARES, E. V. G.; SILVA, L. M. F. Estudo ergonômico e propostas de melhorias em postos de trabalho de uma empresa de mineração. VII SEPRONE Mossoró-RN, 26 a 29 de junho de 2012.

TEIXEIRA, Sarah de Oliveira Lamas.Estudo sobre a prevalência de queixas dos trabalhadores de fábricas de confecção de luvas de couro, localizadas em um município de Minas Gerais. Itajubá, 2012.

VITTA, A. DE.; CANONICI, A. A.; CONTI, M. H. S. DE.; SIMEÃO, S. F. A. P. Prevalência e fatores associados à dor musculoesquelética em profissionais de atividades sedentárias.

Revista Fisioterapia e Movimento, v. 25, n. 2, p. 273-280, Curitiba, abr./jun. 2008.

WORLD HEALTH ORGANIZATION. Obesity: preventing and managing theglobal epidemic. Report of the WHO Consultation on Obesity. Geneva: World Health Organization: 1998. 